\title{
Design of the 08ID-1 Protein Crystallography Beamline at the Canadian Light Source
}

P. Grochulski ${ }^{a}$, I. Blomevist ${ }^{a}$, B. Yates $^{a}$, E. Hallin $^{a}$

AND L. DELBAERE ${ }^{b}$

${ }^{a}$ Canadian Light Source, University of Saskatchewan

101 Perimeter Road, Saskatoon, Saskatchewan S7N 0X4, Canada

${ }^{b}$ Department of Biochemistry, University of Saskatchewan

107 Wiggins Road, Saskatoon, Saskatchewan S7N 5E5, Canada

We describe the design of the Canadian Macromolecular Crystallography Facility 08ID-1 protein crystallography beamline that is being built at the Canadian Light Source. An in-vacuum small gap undulator will illuminate the beamline providing high X-ray brilliance and beam properties a vailable at the Canadian Light Source that will allow studying small crystals $(>20 \mu \mathrm{m})$ and crystals with large cell dimensions $(<1000 \AA)$. The planned automation of the beamline will allow for its remote usage.

PACS numbers: $41.50 .+\mathrm{h}$

\section{Introduction}

The Canadian Light Source (CLS) will be a $2.9 \mathrm{GeV}$ synchrotron light source. The Protein Crystallography (PX) beamline is one of the first group of seven approved beamlines which is being built at the facility. Single crystal X-ray diffraction of biological macromolecules has arguably become the most important experimental technique to elucidate the structure of biological macromolecules at the atomic level [1]. In recent years the technique has produced the detailed structures of thousands of proteins and other macromolecules [2]. These structures have contributed to the understanding of fundamental processes in virtually all fields of biological and medical sciences.

Recently the explosion of genetic sequences from the Human Genome Project and a number of technical advances in structure determination have created the structural genomics field [3]. It arose out of a desire of scientists to obtain structural 
data, and eventually functional information, about all known proteins based on the identification of protein families. A consequence of these efforts will be the production of large quantities of small crystals to be measured at synchrotron facilities.

Studying small crystals of large biological molecules requires the high X-ray brilliance and beam properties available from the in-vacuum small gap undulator (SGU). It also requires easy and precise tuning of the X-ray energy in order to use the powerful tool of multiple-wavelength anomalous dispersion (MAD) phasing, which today is the most accepted method of solving new protein structures [4]. The beamline requires superior optics with inherent focusing capability in the horizontal and vertical dimensions, to get a very small beam size at the sample. Moreover, the beamline must be as long as possible to obtain high demagnification. With the predicted large number of crystal samples to be measured per shift an intense source like the SGU at the CLS will be required, coupled with a highly efficient and productive beamline design.

\section{Instrumentation}

\subsection{General description}

At Canadian Macromolecular Crystallography Facility (CMCF) a $1.6 \mathrm{~m}$ long small gap in-vacuum undulator located in the 08 straight section will illuminate the PX beamline. The SGU will be located upstream from the center of the straight section in a chicaned position, which will allow a second SGU in this section in the future. The SGU will be a hybrid undulator with a $20 \mathrm{~mm}$ period, set at a minimum gap of $5 \mathrm{~mm}$. The predicted performance of the undulator is shown in Fig. 1. The expected flux on the $0.15 \mathrm{~mm} \times 0.05 \mathrm{~mm}(\mathrm{~h} \times \mathrm{v})$ sample will be $\sim 5 \times 10^{12} \mathrm{ph} / \mathrm{s}$ at $12 \mathrm{keV}$ using the seventh harmonic and a Si(111) double crystal monochromator.

The general layout of the beamline is shown in Fig. 2. The main optical elements of the PX beamline include: primary aperture (water-cooled mask), double crystal monochromator with the cryogenically cooled first crystal and sagittally bent second crystal, mirror, Bremsstrahlung collimators and stop, synchrotron radiation photon beam stop, adjustable guard slits and photon shutter. The beam will be horizontally focused by the sagittally bent crystal of the monochromator and vertically focused by the $1.0 \mathrm{~m}$ long bent mirror, which will also remove higher harmonics. A number of beam position monitors and reference detectors will be included in the optics configuration. The beamline will be initially commissioned with the front end separated by a beryllium window.

General specifications of the PX beamline are given in Table I. The most valuable absorption edges for the resonant crystallography are between 11.5 and $12.66 \mathrm{keV}$ (Se $K$-edge; $L_{\mathrm{III}}$-edges of $\mathrm{Pt}, \mathrm{Au}, \mathrm{Hg}$ ). We anticipate that most of the user community will prefer to use X-ray energies in the range of $6.5-18 \mathrm{keV}$ : 


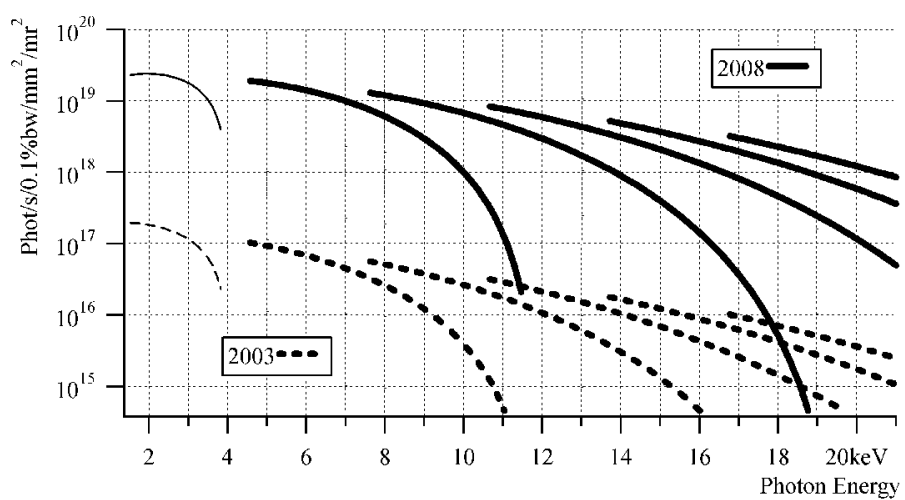

Fig. 1. Brightness of the SGU in 2003 (dotted line) and in 2008 (solid line). The thicker lines show the harmonics that will be used to cover the $6.5-18.0 \mathrm{keV}$ range.

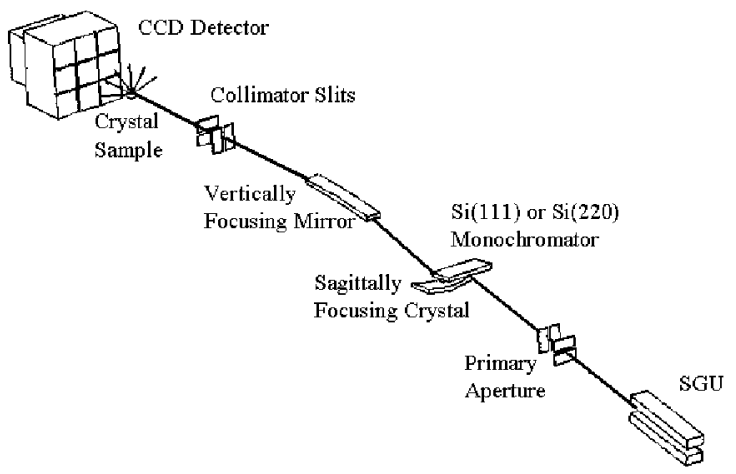

Fig. 2. Layout of the CMCF 08ID-1 beamline.

a range encompassing the absorption edges of the heavy atoms most commonly used for crystal structure analysis: $K$-edges between $6.5-18.0 \mathrm{keV}$ include $\mathrm{Mn}, \mathrm{Fe}$, $\mathrm{Co}, \mathrm{Ni}, \mathrm{Cu}, \mathrm{Zn}, \mathrm{Ga}, \mathrm{Ge}, \mathrm{As}, \mathrm{Se}, \mathrm{Br}, \mathrm{Kr}, \mathrm{Rb}, \mathrm{Sr}, \mathrm{Y}, \mathrm{Zr}, \mathrm{Nb}, \mathrm{Mo}$; $L_{\mathrm{III}}$-edges between $6.5-18.0 \mathrm{keV}$ include all elements with $Z>62$ (samarium - uranium).

TABLE I

General specifications of the 08ID-1 beamline.

\begin{tabular}{|c|c|}
\hline Spectral range & $6.5-18.0 \mathrm{keV}$ \\
\hline $\begin{array}{l}\text { Flux on the sample } @ 12 \mathrm{keV} \\
\text { ( } 7 \text { th harmonic) }\end{array}$ & $\sim 5 \times 10^{12} \mathrm{ph} / \mathrm{s}(\operatorname{Si}(111))$ \\
\hline Brilliance@12 keV (7th harmonic) & $\sim 10^{18} \mathrm{ph} / \mathrm{mm}^{2} / \mathrm{mrad}^{2} / 0.1 \%$ bandwidth \\
\hline Energy bandwidth $(\Delta E / E)$ & $1.4 \times 10^{-4}(\operatorname{Si}(111))\left(5.5 \times 10^{-5}(\operatorname{Si}(220))\right)$ \\
\hline $\begin{array}{l}\text { Focused spot size at the sample } \\
\text { (horizontal } \times \text { vertical) }\end{array}$ & $0.15 \mathrm{~mm} \times 0.05 \mathrm{~mm}(\mathrm{FWHM})$ \\
\hline Beam crossfire at the sample & $0.65 \mathrm{mrad}$ \\
\hline
\end{tabular}


The end station will be equipped with a goniostat, a CCD detector, a sample cryo-cooling system, a fluorescence detector, a timing shutter, video cameras, and an automated crystal mounting system. Advanced user interface and control software, together with fully automated robotic sample mounting and alignment will allow data collection with remote observation.

\subsection{Monochromator}

The Rosenbaum-Rock monochromator was initially designed and implemented at the X9 Beamline at National Synchrotron Light Source (NSLS) [5] and then the cryo-cooled version was developed at the Advance Photon Source. It is a double-crystal monochromator with a fixed exit height. At the 08ID-1 beamline the first crystal will have a hockey puck shape with cooling fins located opposite to the active area [6]. The second crystal will be very thin $(\sim 0.5 \mathrm{~mm})$, to permit it to be sagittally bent [7]. The crystal will be $25 \mathrm{~mm}$ wide and $76 \mathrm{~mm}$ long with its sides glued to aluminium wings, which will provide the bending moment of the crystal.

The first crystal is mounted on a chi-rotation axis, which allows exact parallel alignment of the lattice planes of the first crystal and a second crystal in the direction perpendicular to the Bragg angle. The second crystal is mounted on an $(x, y)$ translation stage. Movement along the beam $(x)$ axis allows interception of the diffracted beam from the first crystal by the center of the second crystal. The vertical movement $(y)$ allows constant exit height. A vibration isolation base isolated from the vacuum envelope will support the monochromator. The monochromator's specifications are given in Table II.

TABLE II

Specifications of the monochromator.

\begin{tabular}{l|l}
\hline \hline Spectral range & $6.5-18.0 \mathrm{keV}$ \\
Bragg-angle reproducibility & $2 \mu \mathrm{rad}$ \\
Crystal & Si(111) or Si(220) \\
First crystal & cryo-cooled \\
Second crystal & Sagittally bent \\
Bragg angle range & $6.5-38 \mathrm{deg}$ \\
Beam offset & $31 \mathrm{~mm}$
\end{tabular}

\subsection{Mirror}

The bent mirror will focus the photon beam vertically and remove higher order harmonics. The specifications of the mirror are given in Table III. The mirror will be placed immediately downstream of the monochromator. Focussing will be achieved by dynamically bending the flat mirror substrate around a horizontal 
Specifications of the mirror.

\begin{tabular}{l|l}
\hline \hline Substrate & ULE plane mirror of $1000 \mathrm{~mm} \times 90 \mathrm{~mm} \times 43 \mathrm{~mm}$ \\
& $(\mathrm{~L} \times \mathrm{W} \times \mathrm{H})$ clear aperture \\
Surface & 2 Årms roughness and $1 \mu \mathrm{rad}$ surface figure error \\
Coating & $\mathrm{Pt}$, none, Pd coating stripes $(30 \mathrm{~mm}$ wide across width) \\
Bending mechanism & Dynamic, independent at both ends \\
Aberration correction & Via elliptical bending
\end{tabular}

axis. The mirror substrate, made of ultra low expansion (ULE) glass, will be divided laterally into three areas, each $30 \mathrm{~mm}$ wide. One stripe will be coated with platinum, the second will be uncoated and the third will be coated with palladium. The use of the appropriate surface keeps the vertical deflection angle (about $2.5 \mathrm{mrad}$ ) in a small range thus minimizing the vertical translation of the experimental station.

\section{Ray-tracing}

The ray-tracing for the 08ID-1 beamline was done using SHADOW software [8] and the ray-tracing result is shown in Fig. 3. Calculations were done without surface effects (slope errors and roughness). The location of the components and demagnifications are shown in Table IV.

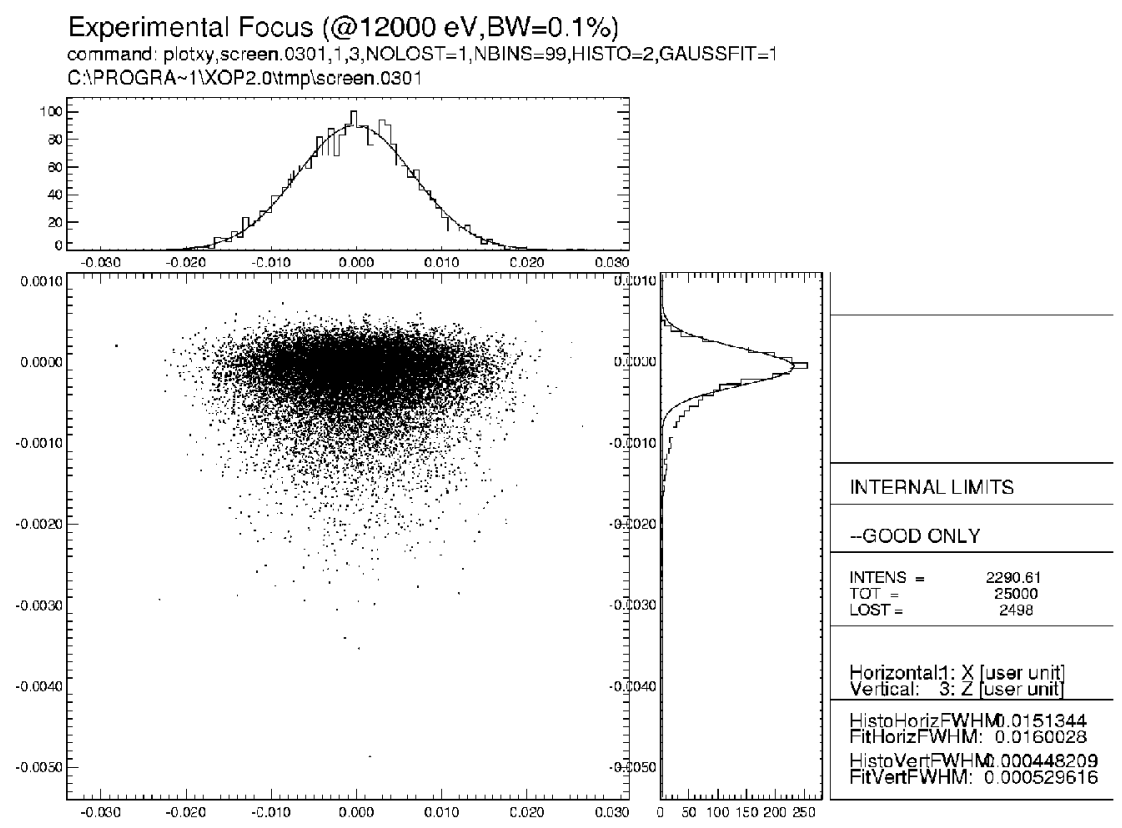

Fig. 3. SHADOW ray-tracing results - focus on the sample. 
TABLE IV

Location of the optical components from the center of straight section 08 .

\begin{tabular}{l|c}
\hline \hline Component & Location $[\mathrm{m}]$ \\
\hline Center of SGU & -0.955 \\
Front end aperture $(2.78 \mathrm{~mm} \times 1.39 \mathrm{~nm})$ & 12.965 \\
Primary aperture $(6.0 \mathrm{~mm} \times 2.0 \mathrm{~mm})$ & 40.842 \\
First crystal of Si $(111)$ monochromator & 42.444 \\
Second Si $(11)$ crystal of monochromator at $12 \mathrm{keV}$ & 42.534 \\
Mirror & 44.613 \\
Specimen & 49.462 \\
Horizontal magnification & 0.160 \\
Vertical magnification & 0.106
\end{tabular}

\section{Summary}

The CMCF 08ID-1 beamline at Canadian Light Source will be a MAD beamline, capable of delivering a photon flux of $\sim 10^{12} \mathrm{ph} / \mathrm{s}$ at $0.15 \mathrm{~mm} \times 0.05 \mathrm{~mm}$ focal size within the range of $6.5-18.0 \mathrm{keV}$. The SGU, coupled with a strong demagnification environment, will allow data to be collected from small crystals ( $>20 \AA$ ) and crystals with large cell dimensions $(<1000 \AA)$. The experimental station will be equipped with a robotic sample placement and alignment system allowing remote access, which will increase the efficiency of structure determination.

\section{Acknowledgments}

The authors wish to thank Dr. Gerold Rosenbaum for his valuable contribution to the project.

\section{References}

[1] C. Branden, J. Tooze, Introduction to Protein Structure, 2nd ed., Garland Publishing Inc., New York 1999.

[2] H.M. Berman, J. Westbrook, Z. Feng, G. Gilliland, T.N. Bhat, H. Weissig, I.N. Shindyalov, P.E. Bourne, Nucleic Acids Research 28, 235 (2000).

[3] R.C. Stevens, S. Yokoyama, I.A. Wilson, Science 294, 89 (2001).

[4] W.A. Hendrickson, J. Synchrotron Rad. 6, 845 (1999).

[5] G. Rosenbaum, L. Rock, K. Sullivan, S. Khalid, Nucl. Instrum. Methods Phys. Res. A 266, 475 (1988).

[6] I. Ivanov, G. Rosenbaum, J. Chrzas, R. Fischetti, C.U. Segre, L.D. Chapman, AIP Conf. Proc. 521, 271 (2000).

[7] G.E. Ice, C.J. Sparks, J. Opt. Soc. Am. A 11, 1265 (1994).

[8] C. Welnak, G.J. Chen, F. Cerrina, Nucl. Instrum. Methods Phys. Res. A 347, 344 (1994). 